\title{
EESTI NUKUNIMETUSED
}

\author{
VILJA OJA
}

Annotatsioon. Laste mänguasjaks oleva nuku peamised eestikeelsed nimetused on nukk, pupe ja titt. Saksa laenu pupe põhitähenduseks eesti keeles ongi 'nukk'. Sama tüvega noomenid, nagu nt puppa, pup(pe), pop(pe), tähistavad nukku paljudes Euroopa keeltes, eelkõige romaani ja germaani keelte murretes, aga ka slaavi jt keeltes. Põhjaeesti murdes nukku märkiv titt : tite on eesti keeles laiemalt tuntud tähenduses 'imik, vastsündinu, väikelaps'. Seda on peetud slaavi laenuks. Sarnase tüvega nukunimetus slaavi keeltes puudub, aga esineb mõnes saksa ja friisi murdes. Sõnal nukk on nii murretes kui ka kirjakeeles palju funktsioone. Mänguasja nimetus on tavaliselt $u$-tüveline $n u k k: n u k u$. Sõna päritolu pole selge. Võimalik, et titt ja nukk on alamsaksa laenud ja et kolm põhilist eestikeelset nukunimetust seostuvad lekseemidega, mis indoeuroopa keeltes on väljendanud ka mõisteid '(last) imetama', 'naiserind', imik'.

Võtmesõnad: eesti murded, etümoloogia, sõnalevik, nukk, pupe, titt

\section{Sissejuhatus}

Mõiste 'nukk' hõlmab tänapäeval mitmesuguseid elusolendeid kujutavaid esemeid, nagu nukuteatri ja -filmi tegelasi, mannekeene, tootemeid, maskotte jm kujukesi. Kultuurisüsteemi arvestades on Juri Lotman juhtinud tähelepanu asjaolule, et olenevalt laste ja täiskasvanute erinevast mõttemaailmast, käitumismallidest ning nuku eri funktsioonidest nende jaoks ei saa laste mänguasjaks olevat nukku samastada inimesesarnase kujukesega. Mõiste „nukk kui mänguasi” on lähtekujutlus, mille alusel on tekkinud kultuurilis-sekundaarne kujutlus „nukk kui mudel” (Lotman 1990: 386). Alljärgnevalt käsitletakse sõnu, mis eesti murretes on tähistanud just laste mänguasjaks olevat nukku.

Laste mängumaailmas on inimesi sageli asendanud puupulgad ning heinast, lõngast, riidetükkidest jms kokku keeratud nukud. Kaltsu- ja riidenukke on eesti lastele valmistanud nii emad-vanaemad kui ka lapsed ise.

1 Uurimistööd on rahastanud SF0050037s10 ja ETF-i grant 7717. 
Lääne-Euroopa, eelkõige Saksamaa meistrite valmistatud nukud jõudsid siinse jõukama klassi kodudesse reisil käinute või kaupmeeste vahendusel. XIX sajandi teisest poolest alates on Saksamaalt, Prantsusmaalt ja Venemaalt toodud portselanpeaga nukke. Esimesed tselluloidpeaga nukud saabusid meile XIX-XX sajandi vahetusel samuti välismaalt. Eestis tekkis nukutööndus alles XX sajandil. Aastail 1920-30 tegid riidenukke müügiks väikesed töökojad ja kodus töötavad käsitöölised. Papjeemašeest (< pr papier mâché, s.o paberist, liimist, kipsist jm komponentidest kokku segatud mass) nukupäid ja nukke hakati siinsetes väikestes kodutöökodades valmistama 1930. aastatel. ${ }^{2}$

Peale kirjakeelse nimetuse nukk kasutatakse eesti murretes muid sellega võrdväärseid nimetusi. Mõne sõna päritolu on seni ebaselge nagu ka vahekord teiste häälikuliselt samasuguste murdesõnadega. Käesolevas artiklis on analüüsitud mõiste 'nukk' kohta Eesti Keele Instituudis eesti murdesõnavara kogus (EMSK) leiduvat ainest ning võrreldud seda sarnaste sõnadega teistes Euroopa keeltes. Murdenäidete kirjaviis ja murdenimetuste lühendite süsteem järgib „Eesti murrete sõnaraamatu” traditsiooni (vt EMS I: 33-37). Teiste keelte puhul on kasutatud Euroopa keelte atlase „Atlas Linguarum Europae” (ALE) jaoks kogutud materjali, mis kajastab XX sajandi murdekeelt kaardistuspunktidest maksimaalse tihedusega $1: 2000 \mathrm{~km}^{2}$ (vt Alinei 1983: XXXIV).

\section{Murdesõnade iseloomustus ja levik}

Eesti murretes tähistavad nukku peamiselt kolmest tüvest - nukk, titt ja pupe - lähtuvad noomenid: 1) nukkg nuku Sa Muh Mar (g nuko) Han Juu JMd Iis KJn T Krl Har, g nukku Lüg; n, g nuku Vll Muh Han Nis Trm Plt; nukku g nugu, nukke g nuge Vai; 2) pupe Jäm Khk Muh Rei Mar Han Pä Nis Kod Plt KJn M T Plv Räp; puppe IisR Vai; pupi Vil; puṕp g puṕi V; 3) titt (tit't) g tite (tit'e) sporaadiliselt eP, tide Kuu, g titte R (n titte VNg Vai) (EMSK) (vt kaart).

${ }^{2}$ Vt ka http://www.mm.ee ja http://linnamuuseum.ee/lastemuuseum. 


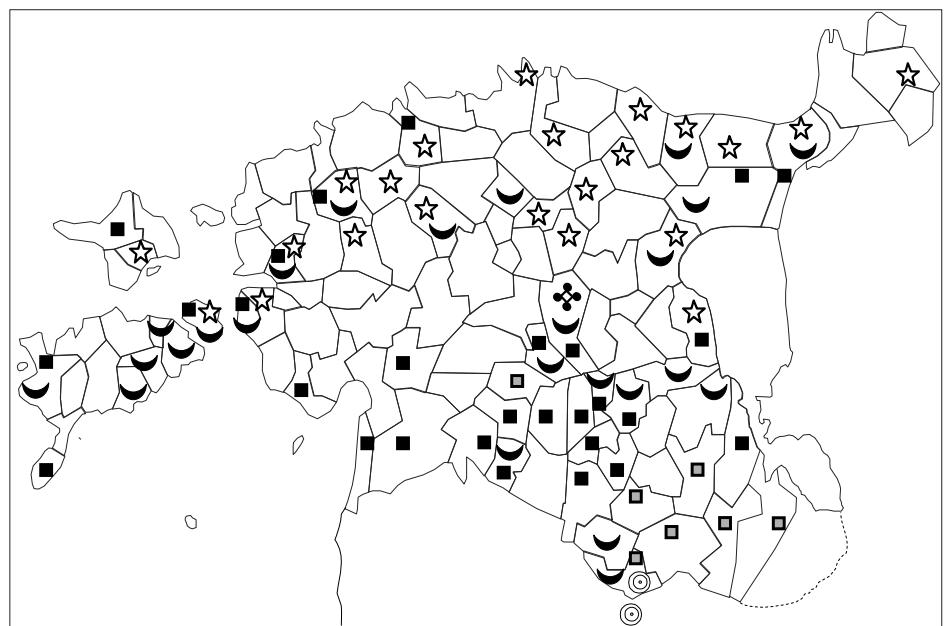

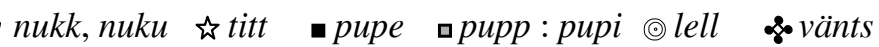

Üksikute teadete kohaselt on nukku nimetatud sõnaga tita, kuid siin võis mõju avaldada Ferdinand Johann Wiedemanni sõnaraamat (1973: 1162), mille alusel sõnavara koguti. Peale nende on registreeritud mõned kitsa levikuga võ juhukasutusega sõnad. Hargla ja Leivu murrakus esineb lätipärane nimetus: Hargla lel'l (g lel'li), Leivu l'ell. Riidest nuku kohta on Põhja-Eestis öeldud vänts : vänsu (Plt) või tite vänts, tite vändsäkus (Juu). Vanades sõnaraamatutes esineb veel Võru tillu, tillo (EKMS II: 429; Wiedemann 1973: 1158) tähendusega 'väike laps, nukk'. Murdesõnavara kogus nuku kohta selline materjal puudub. Kõigist murrakuist ei ole tõenäoliselt nukunimetust küsitud.

Kaardilt näeme, et titt märgib nukku põhjaeesti murde põhja- ja idaosas ning kirderannikumurdes. Sünonüümide võrdlus lubab arvata, et endisel Harjumaal on see nimetus teistest vanem ja murdeomasem. Selle kaudu on seletatud ka uuemaid sõnu, nt Nis nuku, sesamma mis titt; Juu 'enne olid ike tited, nüid ike ‘ütleväd vahel nukud. Tänapäeva kirjakeelne nukk (või nuku) on põhiline nimetus Saaremaa idaosas, Muhus ja Tartu murde põhjaosas, märkides nii omatehtud kui ka ostetud nukku, nt Nõo kakime noid soe ‘tôlvu ('hundinuiasid'), siss teime 'endile nuku. Murdeomane tundub see olevat ka Põltsamaal ja paralleelnimetusena Ida-Virumaal ning Võru murde läänepiiril, nt Jõh titt õli nukku; Plt vänts oli veke nuku; Krl latsõlõ tetäss nukk lupardikõisist. 
Pärnumaal, lõunaeesti murretes ning nendega piirnevatel aladel on ainsa või kõige sagedasema nimetusena registreeritud pupe või pupp. Üksikuid teateid on pupe kohta saarte murdest, Lääne- ja Harjumaalt ning Ida-Virumaalt. Keskmurde alal on pupe väidetavasti olnud teistest nimetustest uuem ning saksikum, nt Jür Vanaste olid meil tited - - aga saksemad ütlesid pupe; Plt pupe ööldi vähä, see lähäb saksa murrakul `väl'la. Sama meelt oli üks Karksi keelejuht, öeldes: pupe om ‘uudine, nukk om vana. Tõenäoliselt võeti see nimetus neis murrakuis käibele mõne teisega paralleelselt, vastandamaks ostetud nukke omatehtud kaltsunukkudele, nt Krk `rõõvast olli iki nuku, pupese olli saksa lastel. Pärnumaal ja suures osas Kagu-Eestist on pupe või pupp XIX sajandil tähistanud omatehtud kaltsunukku, nt Puh ennemb teime 'endile esi pupesit; Urv ku mi latsõ ol'li, sõss meil ol'li ńardsõst puṕi. Seevastu nukk olla Saarde murdesse tulnud alles 1940-ndatel. Hargla murrakus, kus on kasutatud kolme sünonüümi, paistab puṕp olevat teistest vanem ja üldisem nimetus, mille kaudu seletatakse teisi sama tähendusega sõnu, nt Har lel'li?, lel'likese $e^{?}$ kutsutass 'lat'si puṕikese ; taa (laps) vana nuku tädi, taa tege alasi naid puppõ.

\section{Nimetuste päritolu ja tähendusvahekorrad}

Sõna päritolu määramisel võetakse arvesse mitmeid aspekte, nagu häälikkuju ja ootuspäraseid keeleajaloolisi muutusi, semantikat, murdelist levikut ning muidugi teiste keelte võrdlusainest. Ühesuguse (või eeldatavalt varasema sarnase) häälikkujuga sõnade tähendusvahekorrad ühe keele ja isegi murdeala piires pole alati selgelt määratletavad. Võrdlus kontaktkeeltega teeb mõnikord asja lihtsamaks, aga võib ka valele teele juhtida. Vahetevahel aitab eri keelte paralleelseid arenguid tajuda sõnade nimetamismotiiv, st kujutlus, millel mõiste nimetus põhineb. Eesti keeles esinevad nukku märkivad sõnad, eriti nukk ja titt, nii murde- kui ka kirjakeeles mitmes tähenduses. Analoogilisi tähendusvahekordi võib kohata näiteks indoeuroopa keelte nukunimetuste puhul. Seetõttu arutletakse alljärgnevalt sõna tähenduste ja päritolu üle koos. Kolme peamist nukunimetust pupe, titt ja nukk käsitletakse igaüht eraldi alajaotises (3.1-3.3), ülejäänud nimetustest on lühidalt juttu osas 3.4. 


\subsection{Pupe}

Eesti murretes ja kõnekeeles märgib pupe (V puṕp) eelkõige just mänguasja - nukku. Võrdluse vormis on selle sõna abil kiidetud mingit objekti, põhiliselt selle välimust, nt tüdruk kena nagu pupe; lapsed käivad riides kui puped (EKSS IV: 478). Selline võrdlusviis näikse olevat levinud omaette, nukunimetusest sõltumatult, sest esineb ka neis murrakutes, kus nukku märgib mõni muu sõna (nt JMd VMr Lai) või kontekstis, kus võrdlus nuku (ja lapsega) tundub tavatu, nt Jaak Sarapuu: kuhi kui pupe 'hästi tehtud heinakuhi'; Oskar Luts: ilus talu nagu pupe (EKSS IV: 478); Krk miu 'väimiis tegi_śs sanna ku pupe valmiss ilusti; Ran nii ilusa pedäjä seene nigu puped rian.

Meile on pupe laenatud saksa keelest (< sks Puppe 'nukk'), kuhu see omakorda on tulnud ladina keelest (Hogerheijde 1986: 344; Kluge 2002: 730). Sama tüvega noomenid, nagu nt puppa, pup(pe), pop(pe), on nukunimetuseks väga laial alal Euroopas: kõigepealt romaani, aga ka germaani keeltes, mitmes slaavi keeles, mustlaskeeles, kreeka, albaania ja malta murretes. Ladina sõnast püpa (või rahvakeelsest kujust *puppa) lähtunud noomenid tähistavad romaani keeltes nukule lisaks mõisteid 'väike laps' ja '(väike) tüdruk'. Peale selle väljendavad niisugused sõnad ühelt poolt mõisteid 'nisa, nibu, naiserind, lutt' vms (nt vulgaar-lad *puppa, pr poupe, it poppa, albaania púpëzë, lt pups (ning sellest pupa bērns 'rinnalaps, imik'), teiselt poolt 'kimp, pamp, pundar jms' (Buck 1949: 248-249; Pokorny 2002: 848; W-P II: 79-81). Pole teada, milline oli sõna esialgne tähendus. On arvatud, et mõisteid 'väike laps' ja 'nibu, lutt' väljendav sõna võiks olla imemist jäljendav onomatopöa ning ehk oli juba varases ladina keeles kaks juhuslikult sarnase kujuga tüve (Hogerheijde 1986: 343; Meyer-Lübke 1911: 513; W-P II: 79).

\subsection{Titt}

Põhjaeesti keeles teatakse kõikjal (R, eP) sõna titt g tite (tide, titte, harva titi) eelkõige tähenduses 'imik, vastsündinu, väikelaps' ning enamik sellest moodustatud liitsõnu seostub vastsündinud lapsega, nt titeema, titejalg ja -varbad (viimased kaks katsikujootude kohta), titepuder (katsikule viidav puder), titejuuksed. Deminutiivina või lastekeeles on kasutatud ka $e-, i$-ja $u$-lõpulisi nominatiivivorme: Jäm Pil tite, $\mathrm{VNg} t i t i$, Sa Muh titu. Mõnes murrakus väljendab titt : tite silmaava (pupilli), lehepunga või rohttaime 
nuputaolist õit või õisikut. Näiteks põhjarannikul on teelehe täha järgi loodud rahvakeelsed taimenimetused titteleht, teeti(t)eleht ning $(\mathrm{pl})$ teetited (vt Oja 2005: 67). $i$-tüveline titt : titi (tit't $:$ tit' $^{\prime}$ ) esineb murdeis kahes tähenduses: 1) 'tiss' Saaremaal ja Lutsi murrakus ning 2) 'peenis' valdavalt lõunaeesti murdes. Põhjaeestilise nukunimetuse titt levik ja tüvevokaal ühtivad väikest last märkiva sõna omadega.

Noomeni titt : tite etümoloogia kohta on erinevaid arvamusi. Suhteliselt sarnane häälikkuju ja tähendus lubavad omavahel seostada sõnu titt ja tita. F. J. Wiedemann (1973: 1162) peab a-lõpulist kuju tita 'nukk, väike laps (halvustavalt ka täiskasvanust)' deminutiivvormiks sõnast titt, $-e,-a$, mille tähenduseks on sõnaraamatus märgitud 'nukk, nukuke', figuratiivselt 'väike laps'. Julius Mägiste arvates võiks eesti keeles algne olla väikelast märkiv slaavi laen tita, mis on vormilt mugandunud oi-, ei-deminutiividega, kuid säilitanud originaaltähenduse (EEW: 3190; Mägiste 1924: 8, 1928: 16, 30). Andrus Saareste on paigutanud sõnad titt ja tita (lapse ja nuku tähenduses) lastekeele rubriiki (EKMS II: 440-441), ent titt $\mathrm{g}$ tite 'väikelaps, sülelaps, imik' esineb ka neutraalses lapse sünonüümide loetelus (EKMS II: 430).

Hoolimata sarnasest häälikkujust võivad titt ja tita olla eri laenud. Eesti keeles kasutatakse sõna tita või tit'a tavaliselt väikese lapse kohta. Slaavi sõnad vene дumя, bulgaaria dete, sloveeni dete, tšehhi ditě, poola dziecko jt (vrd kirikuslaavi *děte, *dětb) esinevad tähenduses 'laps', aga nukku pole nõnda nimetatud. Et 1 . silbi muutust $-e->-i$ - selles sõnaperes peetakse idaslaavi iseärasuseks, vastab eesti tita häälikuliselt vene sõnale дитя, sobides seega nii sisuliselt kui ka vormiliselt vene laenuks (vt ka Raun 2000: 177). Slaavi keeltes last tähistavad sõnad pärinevad indoeuroopa tüvest *dhei $i$ - (dhe-, dhi- jms), kust on tulnud ka imemist väljendavad verbid, nagu vanaindia dhātave, gooti daddjan, sanskriti dhayati, ladina fêlāre, iiri denim jt, samuti nt vn doumb 'lüpsma' < kirikuslaavi dojiti 'imetama' (Buck 1949: 91; Vasmer 1: 516).

Seevastu titt : tite/titi võis tulla hoopis germaani poolelt. XVII sajandi eesti keelest on kirja pandud titto ja deminutiiv tittoken üksnes nukunimetusena ning liitsõna Titte Emma (= titeema) 'kindbetterin (Eheweib)' (Göseken 1660: 159, 256; Kingisepp jt 2010: 665). XVIII sajandi alguspoole keelt kajastav Salomo Heinrich Vestringi sõnaraamat annab sõna i-tüvelisena: Tit/Tittike samuti just tähenduses 'nukk (Ein Pupchen)'³.

\footnotetext{
${ }^{3}$ http://www.folklore.ee/ kriku/VESTRING/vest_t.htm
} 
Šveitsi saksa murretes märgib diti või titti vastsündinud last ja nukku (viimast ka ühend tolgg diti/titti). Samatüveline deminutiivvorm ditjen on nukunimetus friisi keeles. Alamsaksa keeles oli titte, ditte (dem tittchen, dittichen) ja tiss kasutusel tähenduses 'nisa; naiserind, rinnanibu' (vrd sks Zitze, eesti tiss), nt (Hessen) die mutter gibt dem kind das dittichen (Gutzeit III,2: 27; Grimm: s.v. ditte, titte). Soome murdesõnu titti, titu, titta 'naiserind, lutt' on peetud lastekeelseteks tuletisteks, kuid on ka viidatud sarnastele germaani sõnadele, nagu rts titt (tiss), norra titta 'lehma udar', anglosaksi titt, kasks titte ja saksa Zitze (SKES: 1314). Teisteski indoeuroopa keeltes väljendatakse mõisteid 'nisa; naiserind, lutt' ja '(last) imetama; imema' sõnadega, mis lähtuvad samast tüvest, nt ingl teat (< vana-ingl titt), hisp teta, pr tette 'nisa, lutt' ning hisp tetar, pr téter 'imetama', rumeenia țâță, it tetta (Buck 1949: 248-249, 334; Meyer-Lübke 1911: 662-663; W-P I: 704). Luti asemel anti vanasti lapsele lutsutada riidest keeratud nutsak, mille otsa sisse oli mässitud leiba, mett või muud suupärast. Samasugune riidenutsak oli lihtsaim kaltsunukk, ka selle pea moodustas millegagi täidetud ja nuputaoliseks kinni seotud osa. Niisiis ei pruugi eesti titt olla slaavi, vaid hoopis alamsaksa laen, kuid mõlemal juhul seostub see tähenduselt imikuga ning näib pärinevat sõnast, mille algseks nimetamismotiiviks oli 'nisa, lutt' või 'imema'.

\subsection{Nukk}

Põhjaeesti keeles nimetati kõnealust mänguasja nukuks juba vähemalt XVII sajandil. Heinrich Göseken on saksa Docke tõlkeks märkinud titto/ nuck/nuckoken ja Puppe vasteks [pupa] Nuck/nuckakenne (Göseken 1660: 159, 327; Kingisepp jt 2010: 528). Johann Hornung (1693: 34) on eesti sõna Nuk, G Nukko, Acc. pl. Nukkoid saksa keeles seletanud 'ein zierlicher Mensch'. Eesti keeles esineb nukk mitmes tähenduses ning raske on täpselt määrata, millised neist lähtuvad samast allikast, millised eri allikaist. Wiedemanni sõnaraamat (1973: 692) annab kolm märksõna, kus materjal on jagatud lühidalt kokku võttes järgmiselt: 1) nukk, väljaulatuv ots, kühm, tipp vms; 2) nukk (mänguasi), väike laps, väike inimene; adj: kena, ilus; 3) nurk - eL. Murdekeeles on sõna tarvitatud paljudes tähendustes. Esitan neist osaliselt üldistatud loetelu EMSK näidete põhjal: nukk, millegi väljaulatuv ots, nt maanina, neem, lahesopp, küngas, tipp, mügar, kühm; vankri teljeots, leivapätsi otsatükk; sõrmenukk, sõrmelüli, 
küünarnukk, õlanukk, labaluu ots, põlv, labajalaliiges, jalapäkk; jalatsi, suka, soki, kinda ots; terariista terav ots; kederluu, põseluu, otsmikumõhn, kuklaluu; nina, koon, kärss, suu, nokk; lõngast nupp, sämp, tagi, riideriba, rüiuvaiba narmas; võhumõõk; lõngatokk, lõimelõngade salk, linanuust, kokkuseotud räästavihud; väike heina- või suvivilja hunnik; juuksekrunn; mänguasi, laste kaitsevaim; pruudilinik; nurk, paikkond, ümbruskond; tukastus. Väikeses murdesõnastikus on see materjal jagatud seitsme märksõna alla (VMS II: 105).

Peale eesti keele on nukk- nukunimetuseks soome (põhiliselt KeskSoome), karjala ja lapi murretes: sm nukke, nukki; isuri (Saarove) nukke, krj (Kalevala) nukki; lp (Utsjoki) nuhke $(<\mathrm{sm})$. Karjala maakitsusel ja Põhja-Ingeri soome murretes esineb nukki tähenduses 'väike laps (peamiselt tüdruk)' (Enajärvi 1928: 258; SKES: 397; SMSA). Karjala ńukkero 'väike kõhn olend' võib olla eri algupäraga (Häkkinen 2004: 799-800). Teistes Euroopa keeltes sellesarnast nukunimetust pole.

Nuku etümoloogia on lahtine. Julius Mägiste (1928: 13) käsitles seda deminutiivse tuletisena kindlaks määramata põhitüvest: $<* n u k k(V)-\tilde{o} i$ või *-oi ning ühendas selle kahtlemisi soome keeles narmast või tupsu märkiva noomeniga nukka: nukan. Eesti nuku algne tähendus olnuks siis 'riidelapp, riidetükk' ning edasine areng 'lappidest mängutitt' (Mägiste 1928: 13, 99). Selle variandi põhjenduseks lisab autor sisulise läheduse noomeni nukk : nuku lõunaeestilise tähendusega 'tanu'. Teiselt poolt on aluseks võetud verb nukerdama 'kortsutades, kokku käkerdades hõõruma' vms, mis samuti oleks suguluses soome sõnaga nukka 'karv, narmas' (EEW: 1740; SKES: 397; SSA 2: 236). Võimalikuks on peetud ka laenulist päritolu, seostades seda rootsi sõnaga nock, soomerootsi sõnadega nocka, nåcka (SKES: 396-397) ning alamsaksa keeles linapeod märkiva noomeniga knucke, knocke (Schiller, Lübben II: 505) (vt ka Liin 1968: 328-329).

J. Mägiste pakutud semantilised seosed ja arengud ei tundu tõepärasena, eriti sõnade murdelist levikut arvestades, ent nuku käsitlemine deminutiivse tuletisena näib usutavana (vrd sm nukki, nukke). Germaani keeltest võimalikke vasteid otsides torkas silma, et alamsaksa murretes on sõnad knucke, knocke, nock vms väljendanud osaliselt samasuguseid mõisteid nagu pup-/pop-tüvelised ladina sõnad: 'nisa, nibu, naiserind, lutt', 'kühm; eenduv nukk' ja 'kimp (õlgi, lõnga, lina vms)'. Eelkäsitletud tite ja pupe nimetamismotiivide malli järgi sobiks lapseimetamisega seotud sõna ka eesti nuku laenuallikaks. Saksa kõnekeeles on kasutusel der Nuckel 'lutt' 
ja intransitiivne verb nuckeln 'luttima, lutti imema'. Keskalamsaksa sõnu nückel, nuckel, mis muu hulgas on tähistanud naiserinda ja rinnanibu (nt Põhja-Tüüringis 'lutt' ja 'rinnanibu'), peetakse noomeni nock deminutiivvormiks ning seostatakse tähenduse poolest kuhja, küngast, ümara kujuga kõrgendikku jms või millegi eenduvat otsa, nagu sõrmeotsa ja naelapead, märkiva sõnaga (Grimm: s.v. nückel). Sellise sõna kasutusest tähenduses 'nukk' või 'laps' teateid ei ole. Eesti nukk: nuki 'väljaulatuv ots, kühm, tipp jms' arvatakse olevat laenatud alamsaksa sõnast nok(ke) või rootsi sõnast nock(e) (Raun 2000: 105; SKES: 397). Pole välistatud, et eelkirjeldatud alamsaksa sõnaperest pärineb ka meie mänguasjanimetus.

Kuna nukul on laste mängus inimese roll, on loomulik et nukule kantakse üle inimese nimetusi. Võimalike germaani vastetena tuleksid seega kõne alla mõned naisterahvast märkivad noomenid. Rootsi kõnekeeles märgib nucka vanatüdrukut, murretes on aga nucka (või nocka) halvustava varjundiga nimetus vana naise kohta - 'tühine ( tähtsusetu, töövõimetu, saamatu) vanaeit'. Sellele lähedastes tähendustes esineb sama lekseem teisteski Skandinaavia keeltes (SAOB: s.v. nucka). Saksa keele Tirooli murdes on kasutatud sõnu nock ja betnock märkimaks 'palveõde' ning Šveitsi murdes die nocke tölplasliku naisterahva kohta (Grimm; s.v. nock). On üsna tõenäoline, et eesti-soome nukk on laenatud kas alamsaksa või rootsi keelest, ent olemasoleva teabe alusel midagi kinnitada ei saa.

\subsection{Lell ja muud nimetused}

Hargla lel'l ja Leivu l'ell on läti laenud, vrd lt lelle ja lellis 'nukk; väike laps' < valgevene ljalja (LEW I: 354; ME 2: 449; Vaba 1997: 118). Peale nende keelte tähistab nimetus lèlka, lèle vms nukku leedu murretes ning lal'ka (l'al'ka, lalka, ļaļka) ukraina, bulgaaria, poola ja tšehhi murretes (vt nt Vasmer 2: 551). Eesti deskriptiivsed noomenid vänts ja väntsakas (EEW: 3982) ei ole eelmiste nukunimetustega võrreldavad terminid. Need on tuntud peamiselt põhjaeesti murretes tähenduses 'väike laps, imik' või 'suurekasvuline imik' ning sageli on neil halvustav varjund. Väikest last ja nukku märkiva tillu on Andrus Saareste esitanud nii lastekeelse sõnavara loendis tähendusega 'mänguasi, nukk' (EKMS II: 1028) kui ka väikese lapse nimetusena (EKMS II: 429). Sõna tillu, nagu ka pikemat vormi tilluke(ne), kasutatakse murretes eelkõige omadussõnana 'väike'. Eesti murdesõnavara kogus on mõni lastekeelne näide ka substantiivi tillu 
(til'l|u, -o) kohta, mis märgib pisikest last või looma (nt Kuu tillu pada 'lapse pada'; KJn no til'lu tule 'siiä; Plv mine ’ hältä til'lot 'kiiguta last'), kuid nuku kohta teateid pole.

\section{Kokkuvõte}

Pärnumaal, lõunaeesti murdes ning kohati selle naabruses põhjaeesti murde alal on nuku ainus või kõige sagedasem nimetus pupe (Võru pupp). Titt märgib nukku põhjaeesti murde põhja- ja idaosas ning kirderannikumurdes. Tänapäeva kirjakeelne $n u k k$ (või $n u k u$ ) on põhiline nimetus Ida-Saaremaal ja Tartu murde põhjaosas. Tuumaladele lisaks on pupe ja nuku kohta teateid mujalt, kus enamasti käibib mitu nimetust paralleelselt. Hargla ja Leivu murrakus kasutatakse nimetust lell. Laps enamasti ei vaja nukule eraldi üldnimetust, tema jaoks on see kindla rolliga isik. Arvestades, et ehtsad nukud (või nukupead) toodi meile mujalt (esmalt Saksamaalt) ja et neid tutvustades ning müües tarvitati ilmselt mingit võõrkeelset sõna, ei ole üllatav, kui nukunimetus osutub laensõnaks.

Saksa laen pupe ja läti laen lell esinevad eesti keeles üksnes (või eelkõige) nukunimetusena. Indoeuroopa keeltes on mõlemad lekseemid samas tähenduses laiemalt tuntud. Paljudes Euroopa keeltes väljendavad nukku märkivad mitmetähenduslikud sõnad või nende eelkäijad (nt ladina püpa) osaliselt samu mõisterühmi: 'nisa, nibu, naiserind, lutt', 'kühm; eenduv nukk' ja 'kimp, nuust (õlgi, lõnga, lina vms)'. Noomenid titt ja nukk tähistavad eesti keeles mitut mõistet. Mõlemal sõnal leidub häälikulisi vasteid germaani keeltes. Eesti titt ei pruugi olla laenatud venekeelsest lapsenimetusest, nagu seni arvatud, vaid hoopis alamsaksa sõnast titte vms tähenduses 'nisa; naiserind, rinnanibu, lutt'. Nukk tähistab nukku peale eesti ja soome keele ainult üksikuis isuri, karjala ja lapi murrakuis, nii et selline tähendus võib olla tekkinud läänemeresoome alal. Oletades, et sõna ise on häälikuline laen, võiks seda seostada alamsaksa sõnaga nok(ke) 'eenduv ots, kühm, tipp jms', mille deminutiivvorm väljendab saksa keeles mõisteid 'lutt' ja 'rinnanibu'. Teiselt poolt võib nukk olla rootsi laen. 


\section{Kirjandus}

Alinei, Mario 1983. Introduction. - Mario Alinei et al. Atlas Linguarum Europae (ALE). Volume I, 1. Commentaires. Assen: Van Gorcum, XVXXXIX.

Buck, Carl Darling 1949. A Dictionary of Selected Synonyms in the Principal Indo-European Languages. A contribution to the history of ideas. Chicago, Illinois: The University of Chicago Press.

EEW = Julius Mägiste 1982-1983. Estnisches etymologisches Wörterbuch. Helsinki: Finnisch-Ugrische Gesellschaft.

EKMS II = Andrus Saareste 1959. Eesti keele mõisteline sõnaraamat II. Dictionnaire analogique de la langue estonienne II. Avec un index pourvu des traductions en français. Eesti Teadusliku Seltsi Rootsis väljaanne nr. 3. Stockholm: Vaba Eesti.

EKSS 4 = Eesti keele seletav sõnaraamat. 4. köide (P-R), 2009. „Eesti kirjakeele seletussõnaraamatu" 2., täiendatud ja parandatud trükk. Toim. Margit Langemets, Mai Tiits, Tiia Valdre, Leidi Veskis, Ülle Viks, Piret Voll. Eesti Keele Instituut. Tallinn: Eesti Keele Sihtasutus.

EMS I = Eesti murrete sõnaraamat. I köide (A-J), 1994. Koost. Anu Haak, Evi Juhkam, Mari Must, Mart Mäger, Helmi Neetar, Salme Nigol, Ellen Niit, Vilja Oja, Valdek Pall, Eevi Ross, Aili Univere, Helmi Viires. Käsikirja ühtlustanud ja täiendanud Mari Must. Trükki toimetanud Helmi Neetar, Ellen Niit, Eevi Ross. Eesti Teaduste Akadeemia Eesti Keele Instituut. Tallinn: Eesti Keele Instituut.

Enajärvi, Elsa 1928. Nukke. - Kalevalaseuran vuosikirja 8. Helsinki: Suomalaisen Kirjallisuuden Seura, 258-266.

Grimm = Jacob Grimm, Wilhelm Grimm 1838-1960. Das deutsche Wörterbuch von Jacob und Wilhelm Grimm auf CD-ROM und im Internet. Ein Projekt des Kompetenzzentrums für elektronische Erschließungs- und Publikationsverfahren in den Geisteswissenschaft en an der Universität Trier in Verbindung mit der Berlin-Brandenburgischen Akademie der Wissenschaft en Berlin; http://germazope.uni-trier.de:8080/Projekte/ DWB.

Gutzeit III,2 = Woldemar von Gutzeit 1892. Wörterschatz der Deutschen Sprache Livlands. Th. III, Hälfte 2 (T-Todesgeruch). Riga: In Commission bei N. Kymmel.

Göseken, Heinrich 1660. Manuductio ad Linguam Oesthonicam. Anführung zur Öhstnischen Sprache. Reval: Adolph Simon.

Hogerheijde, Huib 1986. Germanic synthesis of Question ALE-QI: 489, "Doll”. Aspects of Language: Studies in Honour of Mario Alinei. Volume I. Geolinguistics. Papers Presented to Mario Alinei by his Friends and Colleagues of the Atlas Linguarum Europae on the Occasion of his 
60-th Birthday. Editorial Committee: Nils Århammer, A. Hagen, Terho Itkonen, Pavle Ivić, Mieczysław Szymczak, G. Tuaillon. Editorial Secretary Nicoline van der Sijs. Amsterdam: Rodopi, 340-349.

Hornung, Johann 1693. Grammatica Esthonica, brevi, Perspicuâ tamen methodo ad Dialectum Revaliensem. Riga: Literis Joh. Georg Wilck.

Häkkinen, Kaisa 2004. Nykysuomen etymologinen sanakirja. Juva: WS Bookwell Oy.

Kingisepp jt $2010=$ Valve-Liivi Kingisepp, Kristel Ress, Kai Tafenau. Heinrich Gösekeni grammatika ja sõnastik. Tartu: Tartu Ülikooli eesti ja üldkeeleteaduse instituut.

Kluge, Friedrich 2002. Etymologisches Wörterbuch der deutschen Sprache. 24., durchgesehene und erweiterte Auflage, bearbeitet von Elmar Seebold. Berlin/New York: Walter de Gruyter.

LEW I = Ernst Fraenkel 1962. Litauisches etymologisches Wörterbuch. Bd. I (A-privekiuoti). Heidelberg: Carl Winter Universitätsverlag / Göttingen: Vandenhoeck \& Ruprecht.

Liin, Helgi 1968. Alamsaksa laensõnad 16. ja 17. sajandi eesti kirjakeeles. Väitekiri filoloogiakandidaadi teadusliku kraadi taotlemiseks. Käsikiri. Tartu: Tartu Riiklik Ülikool.

Lotman, Juri 1990. Kultuurisemiootika. Tallinn: Olion.

ME 2 = K. Mülenbacha Latviešu valodas vārdnīca. K. Mühlenbachs Lettischdeutsches Wörterbuch. Séjums 2, 1925-1927. Rediǵējis, papildinājis, turpinājis Jānis Endzelīns. Rīgā: Izdevusi Izglìỉbas ministrija.

Meyer-Lübke, Wilhelm 1911. Romanisches etymologisches Wörterbuch. Heidelberg: Carl Winters Univerisitätsbuchhandlung.

Mägiste, Julius 1924. Paar sõna lastekeelest. - Eesti Keel 1, 1-9.

Mägiste, Julius 1928. oi-, e $i$-deminutiivid läänemeresoome keelis. Läänemeresoome nominaaltuletus I. (= Acta et Commentationes Universitatis Dorpatensis B XII 2.) Tartu.

Oja, Vilja 2005. Kasulikul taimel on rohkesti nimesid. - Прибалтийско-финское языкознание: лингвогеографические исследования. Сост. Нина Г. Зайцева. Карельский научный центр. Российская академия наук. Институт языка, литературы и истории. Петрозаводск: Карельский научный центр РАН, 58-75.

Pokorny, Julius 2002. Indogermanisches Etymologisches Wörterbuch. Tübingen/ Basel: Francke.

Raun, Alo 2000. Eesti keele etümoloogiline teatmik. (= Maarjamaa taskuraamat 19.) Brampton/Tartu: Maarjamaa.

SAOB = Svenska Akademiens Ordbok; http://g3.spraakdata.gu.se/saob/.

Schiller, Lübben II = Karl Schiller, August Lübben 1876. Mittelniederdeutsches Wörterbuch. Bd. II (G-L). Bremen: J. Kühtmann; http://www.rzuser. uni-heidelberg.de/ cd2/drw/s/Sa-schm.htm\#Schiller-Lubben. 
SKES = Erkki Itkonen, Yrjö H. Toivonen, Aulis J. Joki 1955-1981. Suomen kielen etymologinen sanakirja. (= Lexica Societatis Fenno-Ugricae XII.) Helsinki: Suomalais-Ugrilainen Seura.

SSA 2 = Suomen sanojen alkuperä: Etymologinen sanakirja. 2 (L-P), 1995. Päätoimittaja Ulla-Maija Kulonen. (= Suomalaisen Kirjallisuuden Seuran toimituksia 556, Kotimaisten kielten tutkimuskeskuksen julkaisuja 62.) Helsinki: Suomalaisen Kirjallisuuden Seura, Kotimaisten kielten tutkimuskeskus.

Vaba, Lembit 1997. Uurimusi läti-eesti keelesuhetest. Tallinn/Tampere: Eesti Keele Sihtasutus, Tampereen Yliopisto.

Vasmer = Макс Фасмер 1986. Этимологический словарь русского языка. 1-2. Перевод с немецкого и дополнения О. Н. Трубачева. Под редакцией и с предисловием проф. Б. А. Ларина. Москва: Прогресс.

Vestring, Salomo Heinrich 2000. Lexicon Esthonico Germanicum [Võrguteavik]. Tartu: Eesti Kirjandusmuuseum; http://www.folklore.ee/ kriku/ VESTRING/index.htm.

VMS II = Väike murdesõnastik. II (M-Ü), 1989. Toim. Valdek Pall. Koost. Anu Haak, Evi Juhkam, Marja Kallasmaa, Ann Kask, Ellen Niit, Piret Norvik, Vilja Oja, Aldi Sepp, Jaak Simm, Jüri Viikberg. Eesti NSV Teaduste Akadeemia Keele ja Kirjanduse Instituut. Tallinn: Valgus.

Wiedemann, Ferdinand Johann 1973. Eesti-saksa sõnaraamat. EstnischDeutsches Wörterbuch. Neljas, muutmata trükk teisest, Jakob Hurda redigeeritud väljaandest. Tallinn: Valgus.

W-P = Alois Walde. Vergleichendes Wörterbuch der indogermanischen Sprachen. I, 1927. II, 1932. Herausgegeben und bearbeitet von Julius Pokorny. Berlin und Leipzig: Walter de Gruyter \& Co.

\section{Sõnavarakogud}

EMSK $=$ eesti murdesõnavara kogu

SMSA $=$ soome murrete sõnaarhiiv 


\title{
Estonian names for 'doll'
}

\author{
Vilja Oja
}

The most frequent and often the only term for 'doll' in Pärnumaa, South-Estonian dialects, and a few nearby locations north of this area is pupe (Võru pupp). Titt is used in the northern and eastern parts of the North-Estonian dialect area and in the coastal dialect. $N u k k$ (or $n u k u$ ) is the prevalent name in eastern Saaremaa and the northern area of the Tartu dialect. Outside the core areas pupe and nukk (nuku) may occur in parallel with some other term. In the Hargla and Leivu subdialects the word is lell.

In Estonian the loanwords pupe (German) and lell (Latvian) denote 'doll' only (or mostly). Both words, in a similar sense, are also well known in IndoEuropean languages. In many European languages the words for 'doll' or their ancestors (e.g. Latin *pūpa, *puppa) partially refer to similar semantic groups: 'nipple, teat, woman's breast', 'bulge, knoll, etc.' and 'bundle, wisp (of straw, hair, flax, cloth, etc.)'.

The Estonian nouns titt and nukk stand for several different concepts. Both words have phonetic counterparts in Germanic languages. The Estonian titt need not have been borrowed from the Russian word for 'child' - instead its ancestor could well have be the Low German titte meaning 'teat, nipple'. As nukk means 'doll' only in Estonian, Finnish, and a few Ingrian, Karelian, and Sami dialects the meaning may have originated in the Finnic area. Supposing the word is a phonetic loan it could be associated with the Low German nok(ke) 'bulge, knoll, etc.', the German diminutive of which refers to 'nipple'. However, nukk could also be a Swedish loanword.

Keywords: Estonian dialects, etymology, geographic distribution, nukk, pupe, titt

Vilja Oja

keeleajaloo ja -teaduse osakond

Eesti Keele Instituut

Roosikrantsi 6

10119 Tallinn

Vilja.Oja@eki.ee 